survey only. The inhibiting compounds have not been tested over a range of concentrations. Differences have been found in the behaviour of whole cells and extracts. Evidence was also found that the $p \mathrm{H}$. optimum of cell extracts was nearer $p \mathrm{H} 7$ than 8 . It should be noted that azide interferes with the colorimetric estimation of nitrite in such a way as to give lower than actual inhibition figures. To avoid this difficulty, the percentage inhibition for azide with a cell extract was derived from the measurement of nitrogen production manometrically. The results quoted are the percentage inhibition of the rate of nitrite reduction.

Inhibition by the last two compounds was relieved by the addition of thioglycollic acid. Tryparsamide did not inhibit. It is possible that a part of the enzyme system involves an active sulphydryl group which is produced under anaerobic conditions. This may not be specifically related to the 'nitritase' system, since an increased activity followed anaerobic growth in the absence of nitrite.

Department of Biochemistry,

Jean B. YouatT

University of Leeds.

Jan. 16.

\section{Effect of DDT on the Metabolism of Khapli Wheat Seedlings}

JoHNsoN ${ }^{1}$ reported that DDT (dichlorodiphenyltrichloroethane) affected the metabolism of Khapli wheat so that the seedling leaves became susceptible to a race of Puccinia graminis var. tritici to which they are normally resistant. The response to DDT was highly specific, as only one other of the resistant wheats tested (Arnautka) showed any indication of susceptibility consequent on spraying.

To determine the specific nature of the response of Khapli wheat leaves to DDT, alcoholic extracts were obtained from DDT-treated and non-treated leaves, 2, 6, 9 and 14 days after treatment. The extracts were concentrated in vacuo and, after a short period of storage in toluene, they were chromatographed using $n$-butanol - formic acid - water mixture as used by Wiggins and Howarth ${ }^{2}$. A visual comparison of the spots on the chromatograph revealed a marked change, as a consequence of the leaf being sprayed with DD'T solution, in the con-

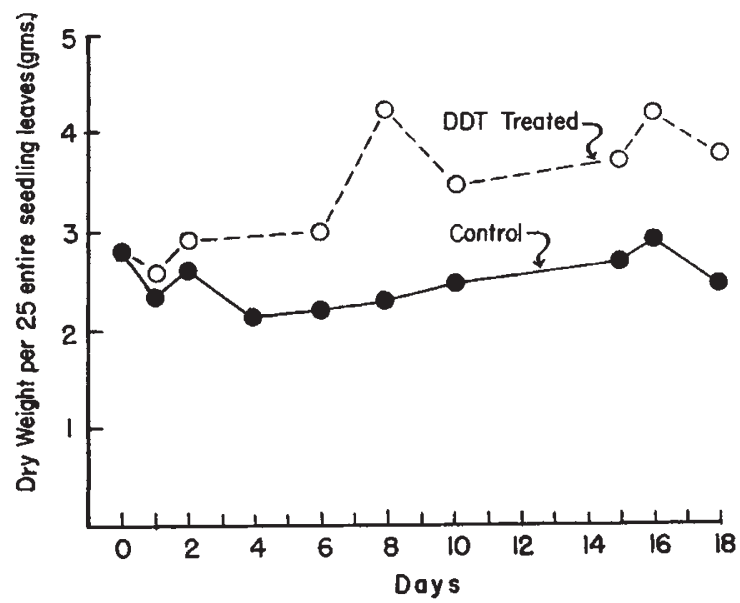

Fig. 1. The effect of DDT, during ontogeny, on the dry weight of the seedling leaf of Khapli wheat centration of amino-acids present in sufficient quantity to be detected by $0 \cdot 1$ per cent ninhydrin. Whenever an amino-acid is present in both the extract from the control and the treated leaves, it is present in greater amount in the latter.

Preliminary results with the chromatography of the simple sugars present in the alcoholic extracts reveal that they also are present in greater quantities in the DDT-treated leaves than in the non-treated leaves.

This study is part of an attempt to determine the nature of rust resistance. Evidently the DDT alters the metabolism in such a way that free amino-acids and simple sugars accumulate in the leaf. The effect may be due to an inhibition of synthesis of proteins and carbohydrates. However, the dry weight of the treated seedling leaf increases more rapidly than does that of the non-treated leaf (see Fig. 1). This would suggest that certain substances that normally are transported during the ontogeny of the leaf are not translocated from the treated seedling leaf. In any event, the observations recorded here prove that DDT extensively alters the metabolism of the Khapli wheat seedling. Further study should reveal which, if any, of these alterations are responsible for the increase in susceptibility of the seedling.

Plant Pathology Laboratory,

Science Service, Canada Agriculture, Winnipeg, Manitoba.

Oct. 28.

${ }^{1}$ Johnson, T., Can. J. Res., C, 24, 23 (1946).

${ }^{2}$ Wiggins, L. F., and Howarth, W. J., Nature, 170, 279 (1952).

\section{Development of the Syncytial Endosperm of Cocos nucifera}

DUTT $^{1}$ has recently summarized her investigations on nuclear behaviour in the developing endosperm of Cocos nucifera. Several of her observations are at variance with statements we have previously made $e^{2,3}$ and with some of our more recent findings ${ }^{4}$. Since these divergent opinions arise in part from a difference in terminology and in part from misinterpretations of the anatomical structure of the coconut, we wish to present several points to clarify this matter.

Following fertilization, the embryo sac of Cocos enlarges rapidly and becomes filled with a clear watery fluid (milk) in which large amoeboid nuclei and fine cytoplasmic particles are suspended. This milk will be referred to as the 'liquid syncytium'. Dutt has not been able to detect free nuclei in this liquid syncytium in the early stages of its development; but they may be easily demonstrated by centrifuging the milk and examining the sediment. Since they are widely dispersed in the liquid they might easily be overlooked in unconcentrated milk. After fertilization, and until the fruit reaches an overall length of approximately $150 \mathrm{~mm}$., an examination of the sac cavity reveals that its boundary is composed of a closely packed layer of isodiametric cells which represents the specialized wall of the inner integument. According to Quisumbing and Juliano $^{5}$, the nucellus is digested prior to fertilization, and therefore this specialized cell layer probably represents an integumentary tapetum or endothelium. The endothelium is in direct contact with the milk and there is no cellular endosperm present at this stage. We have previously referred to this layer as 